\title{
Liberty, Mill, and the Framework of Public Health Ethics
}

\author{
Madison Powers, Ruth R. Faden, and Yashar Saghai
}

\begin{abstract}
In this article we address the relevance of J.S. Mill's political philosophy for a framework of public health ethics. In contrast to some readings of Mill, we reject the view that in the formulation of public policies liberties of all kinds enjoy an equal presumption in their favor. We argue that Mill also rejects this view and discuss the distinction that Mill makes between three kinds of liberty interests: interests that are immune from state interference; interests that enjoy a presumption in favor of liberty; and interests that enjoy no such presumption. We argue that what is of focal importance for Mill in protecting liberty is captured by the essential role that the value of self-determination plays in human well-being. Finally, we make the case for the plausibility of a more complex and nuanced Millian framework for public health ethics that would modify how the balancing of some liberties and public health interests should proceed by taking the thumb off the liberty end of the scale. Mill's arguments and the legacy of liberalism support certain forms of state interference with marketplace liberties for the sake of public health objectives without any presumption in favor of liberty.
\end{abstract}

\section{Introduction}

Public health policies implemented by the state can affect a cluster of related moral interests that individuals have in personal autonomy, the exercise of choice, living under social and institutional arrangements that foster self-directing lives, and securing control over private matters. Popular as well as academic discussions of public health policies bearing on matters as diverse as reproduction, immunization, smoking, automobile safety, and dietary risks of disease often proceed with the assumption that there is a presumption in favor of individual liberty whenever it competes with public health goals. 
Traditional medical ethics debates similarly focus on the place of autonomy among other competing principles and values within the context of patient-clinician relationships. However, the history of clinical medical ethics offers an imperfect model for thinking about public health ethics (although traditional lines between clinical and other aspects of health promotion are blurring at a rapid pace). Unlike clinical medical ethics, public health ethics directly engages the moral relationship between the state and the individual and thus falls within the domain of political philosophy. Here, a common assumption is that any form of state coercion poses a uniquely troubling moral threat to personal freedom and autonomy. It is often concluded that there is a general presumption in favor of liberty such that a burden of proof lies with the proponent of any state intervention that interferes with its exercise.

We challenge this familiar way of framing public health issues by rejecting a general presumption in favor of liberty. We aim to modify how the balancing of some liberty and public health interests should proceed by taking the thumb off the liberty end of the scale, that is, by arguing against a burden of proof for some liberty interests.

In "Public Health Ethics, the 'Harm Principle,' and Core Liberal Commitments" section, we examine briefly how the work of J.S. Mill has been employed to defend a general presumption of liberty in public health on the grounds that it provides the best account of the unique, core commitments of the liberal tradition. In the section "Mill's Tripartite Division of Liberties," we argue that there are good reasons to think that Mill rejected the kind of general presumption of liberty that this line of argument defends. Though we do not offer a definitive interpretation of Mill, we think that Mill makes an insightful distinction among liberties that are immune from interference, liberties that 
deserve a presumption in their favor, and liberties that do not deserve such a presumption.

This tripartite division of liberties represents a fine-grained, nuanced framework for evaluating public health interventions rather than the familiar alternative that assumes the appropriateness of a general, undifferentiated presumption of liberty. In the section "Mill on Liberty and Self-Determining Lives," we argue that what is of focal importance for Mill in protecting liberty is captured by the essential role that the value of selfdetermination plays in human well-being. The "A Nuanced Millian Framework for Public Health Ethics" section, takes a step back and makes the case for a more complex and nuanced Millian framework for public health ethics, a view building upon arguments presented elsewhere as part of a comprehensive theory of the moral foundations of public health and health policy (Powers and Faden 2006).

The overall purpose of our reconstruction of Mill's line of argument is to demonstrate the reasons that contemporary philosophers interested in the ethics of public health have for endorsing a political framework of this sort and to show how that framework links up with similar strands of argument found in the work of recent liberal political theorists. There are, of course, other important arguments made on behalf of a strong or even conclusive presumption against state interference with the kinds of choices that we deny are due any presumption in the balancing process. ${ }^{1}$ While such views need to be addressed as well, our argument for the differentiation among presumptions due to liberties of various sorts, if successful, removes one important line of defense for the

\footnotetext{
${ }^{1}$ One prominent line of argument not discussed herein is the claim that because the state should be neutral among competing conceptions of the good, even what we take to be matters of considerably less consequence than major life plans or the overall contours of a person's most basic life choices merit the same presumption against state interference. The literature on political neutrality is vast and the meaning and plausibility of a neutrality constraint is contested (Wall and Klosko 2003). Moreover, it is an open question whether such a constraint, if justified, would apply equally to "nonbasic liberties" as a requirement of respect owed by the state to its citizens who hold differing conceptions of the good. These issues are discussed elsewhere (Powers and Faden 2006, 4-45).
} 
view that even the most modest proposals for public health intervention bear a heavy burden of justification.

\section{Public health ethics, the "harm principle" and core liberal commitments}

The most frequently quoted except from the famous passage in Mill's On Liberty summarizing the Principle of Liberty asserts that "the only purpose for which power can be rightfully exercised over any member of a civilized community, against his will, is to prevent harm to others" (Mill 2007, 13). This formulation of Mill's Liberty Principle is one that some (but not Mill) call the "Harm Principle." Numerous contributions to the public health ethics literature put this aspect of the Millian framework front and center, and recent discussions demonstrate its continuing theoretical and practical importance.

Some argue for the need to displace the "Millian paradigm" (Jennings 2009), seeking to dislodge the protection of individual liberty interests and autonomy rights from their perceived privileged position. Others attempt what might be described as supplementation. The Nuffield Council Report, for example, proceeds by specifying additional conditions under which state promotion of public health objectives might be justified on grounds beyond the "harm principle." Among these additional reasons are considerations of justice, such as the importance of reducing health inequalities (Nuffield Council on Bioethics 2007). The underlying assumption of many such arguments is that they centrally defining core commitments of the liberal tradition, informed by Millian arguments and their modern equivalents, require a highly restrictive attitude toward all public health interventions. The resulting interpretation of Mill's Principle of Liberty, as 
applied to public health, is thus a general and stringent presumption in favor of liberty in relation to other interests, defeasible only for reasons pertaining to harm to others.

In the next two sections, we will show that this restrictive construal of the centrally defining, core commitments of liberalism, and of Mill's own arguments as they pertain to the regulation of public health, are misguided. In particular, it is the defense of a blanket presumption in favor of liberty in all matters of state action for the sake of the public's health that we challenge as a commitment required by liberalism in general or by a nuanced understanding of Mill's own arguments.

\section{Mill's tripartite division of liberties}

Consider first the fact that early in the opening chapter of On Liberty Mill poses a question about the degree of protection against coercive interference that should be accorded to liberties of particular types. Initially, his claim is that at this stage in history it should be uncontroversial that liberties of conscience should be viewed as absolute in character (Mill 2007, 15). No one else, including the state, has a morally relevant interest of the sort that earns it a place in any process of balancing against the interest individuals have in liberty of conscience. Mill announces that, although some will find it more problematic, he intends to argue in similar fashion for liberty rights of expression. He then considers whether the same absolute protection might attach to liberty of conduct as well, and at least for some forms of conduct, the ultimate conclusion he expects to defend also warrants absolute protection. Early on, then, we find clues to the basic idea that liberties of various sorts might warrant different degrees of threshold protection. 
In his more specific elaboration late in On Liberty, Mill describes the Principle as composed of "two maxims" (Mill 2007, 94), and he observes that the balance of weight of the various liberty interests covered by the Principle should proceed by way of "general presumptions" (Mill 2007, 77). The upshot is that he ends up defending, first, a strong maxim that accords an absolute or conclusive presumption to some liberties, such that they are not subject to being overridden by any interests asserted by others. On such matters, he notes, the "individual himself is final judge" (Mill 2007, 77). Mill notes, in broad fashion that "over himself, over his own body and mind, the individual is sovereign" (Mill 2007, 13). Such a view allows for neither a calculus of comparative harm that might be caused to others by the exercise of choice within one's sovereign domain of judgment nor the balancing of any other competing interest against liberty interests that are protected by what is, in effect, a conclusive moral presumption.

In contrast, the justificatory standard embodied in the second maxim merely establishes a presumption in favor of liberties of certain kinds, not immunity from interference. The reason is that the exercise of choice in some instances affects "certain interests" of others which ground competing rights claims, and therefore earn a place in some balancing process (Mill 2007, 75). These lesser liberties are still weighty enough to warrant a moral presumption in their favor, but unlike cases involving matters over which the individual is sovereign, they properly may be subject to some balancing.

What has been often ignored is that a number of liberty interests, on Mill's view, appear to fall outside the scope of either type of presumptive moral protection conferred by the Principle. Some choices lie within the jurisdiction of what Mill calls the doctrine of Free Trade, rather than the Principle of Liberty. The distinction and its importance are 
often overlooked, but Mill is quite clear that the differences between the two are significant. He notes that "the principle of individual liberty is not involved in the doctrine of Free Trade" and that this doctrine rests on "grounds different from" those which underlie the principle of liberty (Mill 2007, 95). The reason Mill claims that his Principle of Liberty is not involved in the moral evaluation of the types of state regulations that are governed by the doctrine of Free Trade is that, although the doctrine affects individual choices, it is focally concerned with balancing society's interests in economic efficiency and society's interests in public welfare protection. He offers some examples for which the doctrine of the Free Trade, rather than the Liberty Principle, is meant to apply. They include various forms of consumer product regulation and mandatory hazard labeling, state registries for the purchase of dangerous substances, laws regulating product adulteration, worker safety and wage laws, and a whole host of contract and other market place regulations (Mill 2007, 95-97). Such regulatory targets are precisely the sorts of matters that many traditional public health interventions are designed to address.

The Free Trade doctrine assumes that government restriction on trade is "an evil" to be guarded against, but not because such restriction infringes upon a liberty interest in a manner that grounds either version of the presumption in favor of individual liberty. Mill is explicit in saying that "they are wrong solely because they do not produce the results which it is desired to produce by them" (Mill 2007, 95). In these cases, therefore, where the only reason for state forbearance is economic efficiency or a failure to produce the desired improvement in public welfare, we believe that Mill does not endorse any fixed view about what, if any, moral presumption in favor of liberty is required. Nor does 
he say anything to support the assumption that the moral analysis of public welfare regulation necessarily should proceed with a presumption in favor liberty. The reasons that ground the moral Principle of Liberty are not of the same type that ground the economic doctrine of Free Trade. In the former, the relevant reasons for any measure of state forbearance lie in the distinctly moral interests that individuals have in directing and shaping their own lives. In the latter case, state forbearance is assessed in relation to the balancing of societal interests in overall economic efficiency and societal interests in public welfare protection.

Embedded in Mill's distinction among liberties that are immune from interference, those that warrant a presumption in favor of liberty, and those that fall under the doctrine of Free Trade is the premise that it is a mistake to suppose that liberties of all sorts are on a moral par. They are not appropriately viewed as being on a moral par in the sense that not all stand in an equally privileged position at the front end of a balancing process when liberties conflict with other competing interests.

Mill's distinction among liberties, based on the differential threshold weight that each type of liberty should be accorded, does run counter to some other well-known views within the liberal tradition. Most obviously, within contemporary libertarian political theory there is an implicit moral parity claim regarding the singular standard of justification for all state interferences with liberty. Libertarians often speak as if liberties of all sorts enjoy the same high - often absolute - threshold weight in competition with all other goods or principles. Their singular political aim is to secure individual liberties, small and grand, whenever and however the state can intrude, against the uniformly evil threat of any state interference with choice. However, it would be a mistake to equate the 
libertarian view with all of the liberal tradition. As we have seen, Mill, for one, does not endorse a fully general presumption of liberty. Nor does he endorse a single view of its stringency whenever such a presumption does apply.

\section{Mill on liberty and self-determining lives}

We now turn to our explication of the rationale behind Mill's view that all liberties do not deserve either form of the presumption in their favor. If the Principle of Liberty establishes two types of moral presumption in favor of some individual liberties, and these distinctive moral reasons are different in kind from the public policy reasons in competition under the Free Trade doctrine, what exactly informs this tripartite division of liberties, and why does Mill take such great pains to distinguish them? The answer lies in scattered clues throughout the text of On Liberty and elsewhere, but the clues all point in the same direction. The key factor is that some individual choices merit some degree of strong state protection because of their connection to some crucially important aspect of individual self-determination as an ingredient of well-being. A variety of marketplace choices not implicating the value of leading a self-determining life in the same way do not fall squarely under either of the two moral presumptions afforded by his Liberty Principle.

Mill, of course, is notoriously elusive in his presentation of his case for the value of liberty, in part because his defense rests upon a view of how it figures within his conception of human well-being, which he describes as "utility in the largest sense, grounded on the permanent interests of man as a progressive being" (Mill 2007, 14). Even though an adequate reconstruction of Mill's overall account of well-being (and 
whether Mill remains a utilitarian in good standing) is beyond the scope of our immediate task, there is enough evidence contained in the textual clues to venture a limited hypothesis about the heightened protection he wishes to claim for some liberties, but not for others.

The central lines of the argument in On Liberty focus on the interests that individuals have developing and executing a plan of life (Mill 2007, 57, 59, 104) or participating in "experiments in living" by which individuals may test which modes of living contribute to their well-being (Mill 2007, 57, 81, 106, 110). One strand of Mill's argument emphasizes the claim that leading a self-directed life, one in which individuals exercise and further develop their capacities for determining their own destinies, is itself a constituent of well-being (Mill 2007, 57). Mill also claims that when an individual is free to develop a plan of life, she develops her overall faculties to the fullest degree and thereby advances all other primary elements of her well-being (Mill 2007, 57, 59, 63-64). Leading one's own life, according to one's own lights with regard to its overall shape, is in itself an important constituent of well-being, and it has added instrumental value in the ancillary development of other valuable human faculties that, when richly developed, contribute greatly to human well-being.

What Mill is focally concerned with in the protection of various liberties of thought, expression, and conduct is the vital interest each has in his own "mode of existence" (Mill 2007, 67-68). Mill's talk of a plan of life or experiments in living may strike contemporary readers as overly rationalistic or as excessively deliberative, but the point of his odd locution does not lie in this direction. Mill's focus is on the moral importance of a set of liberties that protect the kinds of choices that structure the course 
of one's life in its most fundamentally defining ways. What the emphasis upon the formulation of an overall life plan - or way of life, or mode of existence - thus suggests is that the core concern of any scheme of protected liberties is not the perceived importance of providing all choices, no matter how quotidian, with either some heightened degree of protection or a blanket immunity from all state-related impediments, on the grounds, for example, that the risks of state oppression are ubiquitous and uniformly comparable. Instead, the argument turns upon the affirmative good Mill thinks is realized by social conditions facilitating the development and exercise of individual capacities, including capacities for self-direction, that are irreplaceable constituents of well-being (Mill 2007, $57)$.

No general presumption in favor of liberty is necessary for the realization of the kind of uniquely important contribution to well-being of concern to Mill. To the extent that Mill's general defense of liberty is predicated upon consequential life choices having a long arc of influence on overall life prospects, one need not have unobstructed choice in every marketplace decision or with regard to every possible course of action as a consumer. Subjecting every public welfare regulation to a presumption of liberty, as if every such regulation should be assumed to have the same sort of profound significance, is at odds with the very rationale upon which Mill attempts to categorize liberties according to the more nuanced degree of protection each deserves.

Critics might reply that any attempt to drive a wedge between the highly consequential, life-shaping choices and the quotidian choices of the sort typical of a host of marketplace decisions is contrary to the sprit of Mill's overall theoretical ambitions to constrain the state. In defense of this view, critics might argue that definitive textual 
evidence to the contrary exists in On Liberty, where Mill says that the "most cogent reason for restricting government interference is the great evil of adding unnecessarily to its power" (Mill 2007, 110). However, that conclusion would be wrong. The cited text occurs in the context in which Mill turns away from his consideration of coercive interferences with liberty to an evaluation of what might be objectionable about state action intended to help citizens by doing beneficial things that individuals would otherwise do for themselves. The evil of interference referenced in this passage is not the evil of coercive interference with individual choice, but rather the evil of well-meaning government action that has the unwanted effect of displacing individual initiative. Nothing in this often-cited passage supports the view that Mill's political theory is overwhelmingly and single-mindedly focused on the evils of state oppression inherent in any form of liberty-limiting state action. In fact, where Mill is most explicit, he takes matters of public welfare regulation out of the domain of the Principle of Liberty and assumes that the centrally defining considerations to be balanced are economic efficiency and public welfare protection.

Our hypothesis, then remains intact. Mill is interested in defending a scheme of stringent liberty protections grounded principally in the special moral significance that attaches to choices that are consequential for an individual's overall life prospects and focally related to control over the shape of a self-determining life as a whole. The proper understanding of Mill's comment on government evil, together with his clear exclusion of various marketplace choices from the scope of either of the two general presumptions arising under his Principle of Liberty, leads us to reaffirm the conclusion that the choices routinely implicated in public welfare regulation are without deep moral significance for 
the broad contours of a life that qualifies as substantially self-determining. In contrast, it is precisely the overall, major life-shaping choices that are of such deep moral significance that the Principle of Liberty is intended to protect.

Mill, of course, grants that state regulation of activities in the marketplace in the interests of public welfare may sometimes impinge on a buyer's interest in forming a life plan, and in those instances, the level of appropriate front-end concern about interference with choices of a particular kind increases (Mill 2007, 96). The contingent fact that regulation of market activities can take on the kind of added moral significance that may bring it under the scope of the Principle of Liberty does not alter the basic claim that, absent very special circumstances and the impact on an individual's ability to determine for himself an overall mode of living, Mill does not view the ordinary marketplace choices of buyers and consumers as appropriately subject to the more demanding strictures of the Principle.

Critics might continue to press the worry that the textual clues in On Liberty are too slender to support the weight of the interpretative hypothesis we offer. However, additional support is articulated often more clearly and more forcefully in The Subjection of Women. In particular, it is in The Subjection of Women that we find a discussion of the "burden of proof" that rests with those who oppose liberty.

Those who oppose equal liberty for women are said to be under a "double burden of proof" (Mill 2007, 120-21). It is important to see just what Mill has in mind when he makes this claim. He is not, for example, arguing that there is a burden of proof imposed upon anyone, who in any given instance, proposes to restrict the range of choices that might be available to an individual under some form of social arrangement. His target is 
something much bigger and quite different altogether than an argument for a presumption of deference to individual choice in any instance in which it might be restricted.

Mill's point is about a way of life, and the necessary degree of immunity from comprehensive forms of external control that are of signal importance. The chief complaint Mill makes against the subjection of women, which he equates with the culturally pervasive, legally enforced regime of wholesale power of men over women, is an evil that he analogizes expressly to the kind of power exercised by absolute monarchs over their political subjects (Mill 2007, 158). The absolute power of husbands over their wives within some legal systems is an equivalent form of despotism, now long rejected, and for the same reasons, the exercise of such power ought to be rejected in the domestic sphere as well (Mill 2007, 153).

The thrust of Mill's argument for equal liberties for women and men rests on the grounds that both have equal interests in making the kinds of life choices that matter centrally to a person who desires to be free from the control and domination of others. The same guarantee of independence that Mill takes as presumptively due to everyone, regardless of gender, is predicated upon the importance of the "same free development of originality in women which is possible to men" (Mill 2007, 143). The conclusion is that what is lost by living under either form of despotism is what he describes as "one of the principal sources of human happiness", the personal satisfaction that comes from the free direction of one's faculties (Mill 2007, 214, 216-17).

That Mill is concerned focally about the liberty to make consequential life choices is confirmed in his selection of examples of the kinds of morally objectionable impediments to equal liberty for women. Decisions about whether and whom to marry, 
admission to professions and careers without restrictions based on gender, control of property and personal assets, control over one's own body and mind, the opportunity for education, for cultural advancement and contribution, and the opportunities for political expression and positions of authority are among the consequential sorts of life choices Mill enumerates. While some other routine choices in one's daily life, when interfered with by the state, may be irksome, inefficient, ill-advised, and foolish, not all are of the sort that undermine one's ability to lead what we call a self-determining life, or what Mill simply describes as a life in which no one is subjugated to the arbitrary and absolute will of another who more or less resembles a political despot in the kind and degree of authority exercised over them (Mill 2007, 129-131). His brief for equal liberty is, as it is in On Liberty, an argument for a substantial measure of individual control over the shaping of one's own life in the kinds of choices that structure the fundamental course of that life.

Moreover, the moral significance of protecting the ability of an individual to shape and direct the broad contours of her own life is claimed by Mill to be a good of incommensurable importance to well-being. The contribution to well-being that would be lost by the absence of a significant degree of self-determination exercised over the primary determinants of one's life prospects is so profound that no other increase in material well-being or other goods can compensate its loss (Mill 2007, 155). In its essence, the heart of Mill's argument for the burden of proof imposed on the opponents of equal liberty for men and women is his claim that the value of personal independence from forms of controlling influence intrinsic to both political and familial despotism is an indispensible ingredient of human happiness. 
Mill's defense of liberty as necessary for human well-being is thus very different from the one that supposes that every impediment to choice is so morally significant that it merits a case-by-case presumption in its favor. On the contrary, the central line of argument in The Subjection of Women, further illustrated by way of his primary examples, suggests that what is principally at stake within Mill's political theory is not simply the value attached to making one's own choices, whenever and however the opportunity might arise, say, for example, as consumers in the marketplace. Rather, what is of special value is a life of self-direction under conditions that permit individuals to determine the broad course of their own lives for themselves, free of the dominion of others who would, in the exercise of that dominion, rob them of an indispensible source of well-being.

\section{A nuanced Millian framework for public health ethics}

We have argued that a suitably nuanced reading of Mill provides an important part of a framework for public health ethics, and for thinking about public welfare regulation more generally. We begin with Mill not only because a particular interpretation of his arguments remains highly influential, but also because we think that the genera thrust of his argument is largely right and that it is consonant with similarly persuasive claims made by recent theorists who are well within the mainstream of liberal political thought. However, we describe our own framework as Millian rather than claim it as Mill's own view in every detail. Our argument is not based on the presumed authority of Mill, any definitive interpretation of Mill (assuming the many strands of his argument admit of such a thing), or the endorsement of all of his particular conclusions. For example, it is not our purpose here to defend or reject the view that there are any 
liberties that warrant absolute protection (as Mill believes), or that in all instances liberties of this sort can be readily distinguished from liberties that warrant a weaker presumption in their favor, or none at all. Rather, we maintain that Mill's tripartite division of liberties and its rationale point in the right direction. In this section, we present two primary reasons why a more nuanced, and indeed, more complex Millian framework provides an attractive alternative to other public health ethics frameworks, and we conclude with a brief comment on how this line of argument connects with some other theories that challenge a different aspect of the kind of Millian framework that we reject.

Our first point relates to the legacy of liberal political theory. Although we do not work under the "default assumption" that liberalism should shape debates about public health practice and policy (Dawson 2009, 122), we do think it is useful to show that what we take to be a nuanced Millian view is not in conflict with this influential tradition. One reason to believe that this is not case is that the rejection of the general, undifferentiated presumption of liberty is echoed in the works of other prominent liberal philosophers, including John Rawls.

One line of argument in Rawls might seem to reveal a major fault line between the Millian framework we endorse and a claim that is central to Rawls's political theory. Lubomira Radoilska maintains, for example, that reliance upon considerations of social justice as grounds for public health restrictions on individual liberty "contradicts the priority of the basic liberties that defines political liberalism" (Radoilska 2009, 140). However, this claim misses the point of Rawls's "priority of basic liberties" thesis, for he, like Mill, has a particular theoretical aim in mind in assigning lexical priority to some but 
not all liberties. The liberties identified by Rawls as deserving to be treated as immune from trade-off against any other welfare or opportunity-enhancing good constitute a special, defined class of liberties that may be sacrificed only for the sake of another basic liberty. This class of basic liberties is narrowly defined to include only some familiar civil and political rights, and it expressly excludes liberties that are denominated as nonbasic. Non-basic liberties are ones pertaining to marketplace activities such as contract and certain forms of property acquisition and transfer (Rawls 1971, 273; Rawls 1993, 291-299). Rawls is clear that while basic liberties can be limited only for the sake of other basic liberties, non-basic liberties can be limited for a broader set of reasons, most importantly, considerations of distributive justice.

Rawls's underlying assumption is thus that all liberties are not "on a par" (Rawls 1971, 273), and accordingly, he does not extend the categorical protection afforded to the basic liberties to every instance in which there is the prospect of state interference with choice (Rawls 1971, 273; Rawls 1993, 291-299). The explicit point that Rawls wishes to make is that some liberties merit differential starting points in the balancing process. The non-basic liberties Rawls identifies are the same sorts of marketplace liberties that Mill seemed to have in mind, and they include concerns about contracts and some types of property rights (Rawls 1971, 273). ${ }^{2}$

Rawls might be read as endorsing some added threshold burden of proof for nonbasic liberties (Freeman 2007, 78). For example, he notes that some moral considerations, in addition to those that are specific to the basic liberties, might provide the appropriate

\footnotetext{
${ }^{2}$ For a discussion of similarities between Mill's and Rawls's views on private property, and the potential influence of the former on the latter, see Persky (2010). Neither of them endorses absolute libertarian property rights or liberty of contract, nor do they argue for in-principle liberty-based limits to interference with marketplace transactions.
} 
basis for a measure of added burden of proof on liberty infringement (Rawls 1993, 296).

In some instances, some "general presumption" for non-basic liberties may be warranted, he says, but not for the same reasons that basic liberties are accorded their lexical priority (Rawls 1993, 291). However, Rawls's explication of that remark reveals that he only intends to say that overriding non-basic liberties requires "good and sufficient reasons" (Rawls 1993, 291). This formulation does suggest that some justification is needed, but not that some sort of burden of proof or added threshold weight is necessary, or that the balancing begins with the scales tipped in any direction. A "good and sufficient reasons" approach signals nothing more than the analogous justificatory standard in legal theory in which a preponderance of the evidence is required in order to decide in favor of either side of a conflict. Unlike other legal standards that demand higher threshold weight, either by way of "clear and convincing evidence" or proof beyond a reasonable doubt, there simply is no case made by Rawls for an assignment of a burden of proof in such matters.

Rawls's argument, like Mill's, makes clear that well within the liberal tradition are arguments in support of the claim that it is important to distinguish between those liberties that are immune from interference (Mill's list partially overlaps with Rawls'), liberties that benefit from a presumption in their favor, and those that lack such a presumption. In addition, Ronald Dworkin makes the similar point effectively in his famous remark that, "I have no political right to drive up Lexington Avenue... It will not do, in the one-way street case, to say that although I have a right to drive up Lexington Avenue, nevertheless, the government for special reasons is justified in overriding that right. That seems silly because the government needs no special justification - but only a 
justification - for this sort of legislation" $(1977,169)$. Here we join Rawls and Dworkin. ${ }^{3}$

Liberty interests matter in any case as concerns that trigger a need for justification, even if they do not loom so large as ones that figure centrally in the value of a self-determining life. The difference is that not all such concerns trigger a presumption in their favor. ${ }^{4}$

There are certainly borderline cases about which we may have a reasonable disagreement. This concession notwithstanding, the point remains that not all public health interventions - even when they take the form of state-imposed bans - implicate liberty interests of the sort that warrant presumptions in their favor.

The second reason we favor a nuanced Millian framework for public health ethics is that self-determination is not only an important element of well-being but an element of well-being that also matters centrally within a theory of social justice that we think of as providing the moral foundation for public health, more broadly (Powers and Faden 2006, 26-29). Our concern expressed under the rubric of "self-determination" is, as it is in Mill's argument, the ability of a person to exert some substantial, though not perfect or complete, control over her or his path through life. Self-determination in this sense is not only a core element of well-being that is of value within a good life independently of all other constituents of well-being, regardless of what whatever else individuals might want. It matters crucially within a theory of justice because leading a self-determining life requires some measure of control over one's fate such that an individual is not merely the

\footnotetext{
${ }^{3}$ There are other liberal theorists who complain about the lack of nuance in some accounts of the weight of liberty interests. David Miller claims that a "line must be drawn between basic freedoms that people should have as a matter of right and what we might call bare freedoms that do not warrant that kind of protection," that is, a presumption in favor of freedom unless there are "strong reasons" for restricting choice (Miller 2007, 204).

${ }^{4}$ James Griffin argues similarly that the libertarian view "misunderstands the political value of liberty" inasmuch as it assumes implausibly that any and all liberties need comparable levels of protection in order for individuals to live as normative agents who place a high value on their ability to play a substantial role in shaping the course of their own lives $(2008,179)$.
} 
instrument of the will of others or of social forces which she has had no role in shaping and which leave her without critical material resources or adequate political standing.

It is not necessary for leading a life that is more self-determining than another kind of life that there be some social structure in which all or as many choices as possible face fewer obstacles, impediments, or external influences. What matters is that we have some significant say over the general course of our lives. Put slightly differently, selfdetermination is about living a life that is not in crucial respects under the domination and control of others or the tyranny of profound necessity. This is a further reason why the central political concerns of public health ethics should be focused on the value of selfdetermination, rather than based on the assumption that all choices are on a moral par. Only on such an assumption would a general presumption in favor of individual liberty is warranted.

The plausibility of our rejection of the blanket presumption in favor of liberty depends on how we might understand the value of self-determination that informs the distinction among the various classes of liberties. Our understanding of the value of selfdetermination can be brought into sharper focus by comparisons to similar, overlapping ideals expressed under different conceptual headings within other contemporary works of political philosophy.

Joseph Raz's well-known ideal of the requirements of an autonomous life has obvious parallels to our account of self-determination. His ideal provides the rationale that he relies upon for the defense of various liberty protections, but in addition, that same rationale underpins the case for other forms of social organization said to be necessary for realizing the full value we should place on the exercise of the capacity for 
autonomy. Raz's general aim is to identify the key constituents or conditions necessary for realizing the ideal of an autonomous life, and his central argument is that for those who value autonomy, they want not merely to have and exercise such a capacity, but to do so in ways that represent its role in contributing to a good life. The ideal is one in which persons are actually able to make something of their own lives according to their own lights, rather than merely being able to navigate an otherwise inhospitable world with few impediments to choice, but also, with few valuable options from which to choose (Raz 1986, 369-374). Raz's ideal thus identifies a rich set of concerns that are very similar to what we subsume under the value we assign to living a self-determining life.

James Griffin is similarly interested in identifying the necessary conditions for realizing the value of what he calls normative agency (Griffin, 2008). To be a normative agent in ways that matter morally (within his specific argument, to be the bearer of human rights) there must be some underlying capacity for self-direction, which he labels as autonomy. Like Raz, Griffin's argument is that our moral interest lies with its successful exercise. Griffin also agrees with Raz that some underlying ideal of the successful exercise of human agency provides the ultimate rationale for the political protection of important liberties, but in addition, that very same rationale is used to underwrite some social guarantee of minimum provision of resources sufficient to make those choices "real" and not merely formally unconstrained. Our theory reaches the same conclusion, arguing that a self-determining life is not merely the ability to shape a life for oneself, but the ability to be self-directing under social conditions that make possible the 
realization of a sufficient level of well-being in all of its core dimensions (Powers and Faden 2006).

Both Griffin and Raz address issues of domination that our account of selfdetermination highlights. This feature of all three accounts is of crucial importance, and it is one that republican political theorists often criticize the liberal political tradition for neglecting. The heart of the republican worry is that fewer external constraints on action may not account for all that an adequate political theory regarding human freedom should take into account (Pettit 1997). The republican claim is that any plausible ideal of a free person within organized society is incompatible with forms of domination that involve the control that some persons can exert over others, even if those in a position to exert control choose not to do so. Raz engages that autonomous agency requires independence from forms of external authority that have the power to exercise control over our lives, at will, and without limit (Raz 1986, 378). Griffin also notes the central importance of an individual's independence from the domination of others, but unlike Raz, he subsumes that concern under his definition of autonomy, which is in turn a constituent of his more encompassing ideal of normative agency (Griffin 2008, 33, 151).

Raz and Griffin thus differ in terminology, but both accommodate worries about domination within their respective ideals, as do we. Our conception of the value selfdetermination incorporates overlapping concerns addressed by both Raz and Griffin, but given somewhat different emphasis in each account. Raz emphasizes the importance of forms of social organization that ensure an adequate range of options, focusing on the set of permissible restrictive social structures necessary to ensure immunity from the domination of others. Griffin emphasizes the importance of social guarantees of 
minimum levels of resource provision at a level sufficient for independence from profound necessity that undermines the successful exercise of normative agency (Griffin $2008,33,151)$. Our view is explicit in its incorporation of both forms of independence that Raz and Griffin emphasize-from the domination of others and from the grip of profound necessity (Faden and Powers 2010). ${ }^{5}$

For a variety of reasons, including the wide variation in philosophical usage surrounding autonomy and the risk of taking on board a variety of ancillary assumptions that we do not endorse, we prefer what we take to be the more straightforward language of self-determination. ${ }^{6}$ That said, the common threads across our account of selfdetermination, and similar ideals of an autonomous life in Raz and normative agency in Griffin, underscore our claim that what is at issue in public health ethics is not a general concern with all liberties but a focal concern with those liberties central to leading a selfdetermining life. Concerns of this sort are ones that other political theories also identify as centrally valuable.

A final observation about the overall shape of our proposed Millian framework is that we concur also with those who argue that there are a plurality of justifications for liberty-limiting public health policies, other than prevention of harm to others (Dawson and Verweij 2008, 194). Although we do not argue the point here, we are sympathetic to

\footnotetext{
${ }^{5}$ There is much to be said about the moral significance of differences in how self-determination is affected adversely by domination and by social structural mechanisms that are not set in motions as part of a larger pattern of oppression or animus toward groups. We address these issues elsewhere (Powers and Faden 2006, 57-79).

${ }^{6}$ Each theory brings its own set of assumptions that we do not necessarily endorse. For example, Raz at times suggests that because some choices are worthless, morally wrong, or repugnant they are not entitled to liberty protection (Raz 1986, 411). Griffin deploys his conception of the value of normative agency as the singular rationale for a theory of human rights. We make neither of these claims. Moreover, the bioethics literature, apart from political philosophy generally, has its own long-standing, internal controversies associated with autonomy and what appropriate respect for autonomy involves (Beauchamp and Childress 2009). We also refrain from using the language of negative versus positive liberty. These categories are far from enjoying universal agreement on what delineates them, and in our judgment, many familiar ways of marking the distinction tend to be more misleading than illuminating.
} 
Alan Wertheimer's arguments that Mill's own text contains a rather extensive catalogue of defeasibility conditions for presumptive liberty rights, apart from the prospect of harm to others (Wertheimer 2002, 38-58), including considerations of justice and the discharge of public burdens. The broader account of the moral foundations of public health and health policy, within which our conception of self-determination is embedded, concurs with those who seek to give a prominent place to multiple considerations of social justice (Powers and Faden 2006). Thus, we think that the best construal of a Millian framework for public health ethics is both more complex than one that supposes only one kind of reason for the defeasibility of any presumptive liberty right, and more nuanced in its recognition that all liberties are not on a moral par and thus, not entitled to either version of Mill's presumption.

\section{Conclusion}

Mill deserves a prominent place in public health ethics, but for the right reasons. A broadly Millian framework for the ethics of public health is plausible only if it is as nuanced and complex as Mill's own theory. It must begin with the recognition that all liberties are not on a moral par, such that liberties in need of the greatest protection are those that are focally important to the value of self determination, and it must conclude with a recognition that even liberties that warrant a presumption in their favor can be defeated by a plurality of reasons. The focus of this article has been on the need for nuance that gives appropriate weight to liberty interests of all types, including those that warrant no presumption whatsoever, by arguing that they should not be restricted without adequate justification in the design of public health and other public welfare measures. 
Penultimate draft, January 2012

Public Health Ethics, 5 (1): 6-15, 2012

Advance access published February 15, 2012

doi:10.1093/phe/phs002

\section{References}

Beauchamp, Tom. L., and James F. Childress. 2009. Principles of biomedical ethics. $6^{\text {th }}$ edition. New York: Oxford University Press.

Dawson, Angus. 2009. Editorial: Political philosophy and public health ethics. Public Health Ethics 2(2): 121-122.

Dawson, Angus, and Marcel Verweij. 2008. The steward of the Millian state. Public Health Ethics 1(3): 1-3.

Dworkin, Ronald. 1977. Taking rights seriously. Cambridge, MA: Harvard University Press.

Faden, Ruth, and Madison Powers. 2010. A social justice framework for health and science policy. Cambridge Quarterly of Healthcare Ethics 30(4): 596-604.

Freeman, Samuel. 2007. Rawls. Oxford: Routledge.

Griffin, James. 2008. On human rights. Oxford: Oxford University Press.

Jennings, Bruce. 2009. Public health and liberty: Beyond the Millian paradigm. Public Health Ethics 2(2): 123-134. 
Penultimate draft, January 2012

Public Health Ethics, 5 (1): 6-15, 2012

Advance access published February 15, 2012

doi:10.1093/phe/phs002

Mill, John Stuart. 2007. On Liberty and Other Writings. Stefan Collini, ed. Cambridge: Cambridge University Press.

Miller, David. 2007. National responsibility and global justice. New York: Oxford University Press.

Nuffield Council on Bioethics. 2007. Public health: Ethical issues. London: Nuffield Council of Bioethics.

Persky, Joseph. 2010. Rawls's thin (Millean) defense of private property. Utilitas, 22(2): 134-147.

Pettit, Philip. 1997. Republicanism. Oxford: Oxford University Press.

Powers, Madison, and Ruth Faden. 2006. Social justice: The moral foundations of public health and health policy. Oxford and New York: Oxford University Press.

Radoilska, Lubomira. 2009. Public health ethics and liberalism. Public Health Ethics 2(2): $135-145$.

Rawls, John. 1971. A theory of justice. Cambridge: Harvard University Press. 
Penultimate draft, January 2012

Public Health Ethics, 5 (1): 6-15, 2012

Advance access published February 15, 2012

doi:10.1093/phe/phs002

Rawls, John. 1993. Political liberalism. New York: Columbia University Press.

Raz, Joseph. 1986. The morality of freedom. Oxford: Oxford University Press.

Wertheimer, Alan. 2002. Liberty, coercion, and the limits of the state. The Blackwell guide to social and political philosophy. Robert L. Simon, ed., 38-59. Oxford: Blackwell. 